\title{
SAHA/Vorinostat induces the expression of the CD137 receptor/ ligand system and enhances apoptosis mediated by soluble CD137 receptor in a human breast cancer cell line
}

\author{
DANIELA BELLAROSA ${ }^{1}$, ALESSANDRO BRESSAN ${ }^{1}$, MARIO BIGIONI ${ }^{1}$, MASSIMO PARLANI $^{1}$, \\ CARLO ALBERTO MAGGI $^{2}$ and MONICA BINASCHI ${ }^{1}$ \\ ${ }^{1}$ Department of Pharmacology, Menarini Ricerche, I-00040 Pomezia; ${ }^{2}$ Menarini Ricerche, I-50131 Florence, Italy
}

Received April 20, 2012; Accepted June 12, 2012

DOI: $10.3892 / \mathrm{ijo} .2012 .1551$

\begin{abstract}
HDAC inhibitors (HDACis) represent a class of anticancer agents including suberoylanilide hydroxamic acid (SAHA, Vorinostat), which has shown a strong antitumor effect, both in vitro and in vivo. Induction of apoptotic genes is an important pathway of SAHA cytotoxic mechanism of action and it has been largely described that SAHA induces sensitization of cell death receptor-resistant breast cancer cells to apoptosis. In this study, we investigated the activation of some apoptotic genes which could be responsible for the in vivo antitumor potency of SAHA in a model of human breast cancer. We found that the apoptotic gene pattern induced by SAHA in the MDA-MB-231 cell line involves the upregulation of some molecules belonging to the TNF superfamily. In particular, we demonstrated that the upregulation of the CD137 receptor/ligand system correlates with a synergistic cytotoxic effect when MDA-MB-231 cells are treated with the combination of SAHA and soluble CD137 receptor. To our knowledge, this is the first study to indicate that this member of the TNF superfamily, CD137, is modulated by SAHA treatment in breast cancer cells, suggesting that the combination of SAHA with this TNF-related receptor could be a new therapeutic approach for the treatment of tumors.
\end{abstract}

\section{Introduction}

Altered acetylation and deacetylation of the histones is often associated with cancer since it causes changes in the expression

Correspondence to: Dr Daniela Bellarosa, Department of Pharmacology, Menarini Ricerche, Via Tito Speri 10, I-00040 Pomezia, Italy E-mail: pharmacology@menarini-ricerche.it

Abbreviations: 7-ADD, 7-aminoactinomycin D; APC, allophycocyanin; Casp, caspase; CI, combination index; ER, estrogen receptor; IC, inhibitory concentration; PE, R-phycoerythrin; sCD137, soluble CD137 receptor; TNF, tumor necrosis factor; TNFRSF, TNF receptor superfamily; TRAIL, TNF-related apoptosis inducing ligand

Key words: HDAC inhibitors, CD137, death receptors, apoptosis, breast cancer cells pattern of genes involved in the regulation of cell proliferation and apoptosis $(1,2)$. It is well known that hyperacetylation of histones $\mathrm{H} 3$ and $\mathrm{H} 4$ correlates with gene activation whereas deacetylation mediates chromatin condensation and gene transcription silencing (3).

HDAC inhibitors (HDACis) are a new group of anticancer agents and are currently evaluated in several phase I and phase II clinical trials in patients with hematologic and solid malignancies $(4,5)$. Five chemical classes of HDACis have been characterized including benzamides (MS-275), hydroxamic acids (SAHA and trichostatin A), short-chain fatty acids (sodium butyrate and phenylbutyrate), cyclic tetrapeptide containing a 2-amino-8-oxo-9,10-epoxy-decanoyl moiety (trapoxin A) and cyclic peptides without the 2-amino-8-oxo-9,10-epoxy-decanoyl moiety (FK228). Recent studies have shown that HDAC inhibitors induce cell cycle arrest, differentiation, and apoptosis in vitro and in vivo (6). HDACis also inhibit endothelial cell proliferation and angiogenesis by down-regulating angiogenesis-related gene expression (7). Two HDACis, SAHA and romidepsin (depsipeptide or FK228), have been approved by the US Food and Drug Administration for the treatment of cutaneous $\mathrm{T}$ cell lymphoma $(8,9)$. Since breast cancer is the highest cause of tumor death in women, the antitumoral potency of HDACis on human breast tumor cells has been widely investigated.

In breast cancer cell lines, SAHA has been demonstrated to suppress the growth of tumor cells in vitro at low micromolar concentrations (10). Growth inhibition was associated with cell cycle arrest, morphological and functional differentiation and apoptosis. In vivo, in tumor xenograft models, SAHA significantly inhibits tumor growth of human breast cancer cells without apparent toxicity in animals (11).

Several studies have demonstrated that HDACis can sensitize cancer cells to apoptosis induced by Apo2L/TRAIL, Gleevec, chemotherapeutic agents and ionizing radiations $(12,13)$, and also sensitization of breast cancer cells to topoisomerase II inhibitors by SAHA treatment has been reported, indicating that HDACis may be capable of enhancing the effectiveness of apoptosis-inducing agents used clinically (14). Although many studies have demonstrated the effect of histone acetylation on the re-expression of ER $\alpha$ receptors (15), the activation/repression by HDACis of apoptotic genes which could counteract the 
aggressive behaviour of ER(-) breast cancer cells is still matter of investigation $(16,17)$.

This study was designed to analyze genes involved in SAHA-induced cell death pathways. In fact we observed a different antitumoral potency of SAHA in vivo and in vitro cytotoxicity experiments on the human breast cancer cell line MDA-MB-231, which is ER(-) and expresses mutant p53, when compared to the ER(+)/wild-type p53 MCF7 cell line. Here, we found that SAHA has different effects on the two breast cancer cell lines, as regard to $\mathrm{H} 4$ histone acetylation, cell cycle, apoptosis kinetics, but above all on the expression of apoptotic genes. In particular TNF superfamily molecules (TRAIL, CD137, CD70/CD27) are strongly upregulated in MDA-MB-231 cells and we demonstrated that the combination of SAHA with the soluble CD137 receptor exerts a synergistic effect on MDA-MB-231 cell death. On the contrary, in MCF7 cells, apoptosis seems to be TNFR-independent and CD137 upregulation is absent. Thus, these results enlarge the field of application of the therapeutical approach which combines HDACis and TNF receptor family molecules, suggesting that the combination of HDACis plus soluble CD137 receptor could be useful in killing CD137L positive human breast cancer cells.

\section{Materials and methods}

Reagents and chemicals. Suberoylanilide hydroxamic acid (SAHA, Vorinostat), was synthesized in the Department of Chemistry of Menarini Ricerche SpA (Pomezia, Italy). DMSO was purchased from Sigma (St. Louis, MO, USA). Anti-CD137-APC and anti-CD137L-PE antibodies and APCand PE-stained isotype controls were purchased from BD Pharmingen (San Diego, CA, USA). FcR blocking reagent and $10 \%$ BSA solution were purchased from Miltenyi Biotech (Bergish Gladback, Germany).

Cell culture. The human mammary adenocarcinoma cell line ER(-), MDA-MB-231, was purchased from ATCC (American Type Culture Collection, VA, USA). The human mammary adenocarcinoma cell line ER(+), MCF7, was kindly provided by Dr F. Zunino (Istituto Nazionale Tumori, Milan, Italy). MDA- MB-231 cells were propagated in Leibovitz's L-15 medium supplemented with $10 \%$ foetal bovine serum (FBS) and $2 \mathrm{mM}$ L-glutamine (Gibco). MCF7 cells were propagated in Eagle's minimum essential medium supplemented with $0.01 \mathrm{mg} / \mathrm{ml}$ bovine insulin, $10 \% \mathrm{FBS}$ and $2 \mathrm{mM} \mathrm{L}$-glutamine. Cells were cultured at $37^{\circ} \mathrm{C}$ in a $5 \% \mathrm{CO}_{2} / 95 \%$ air humidified atmosphere.

Cell treatments. In apoptosis experiments, sub-confluent cells were cultured for 24- or 48-h in the presence of equitoxic concentrations of SAHA, corresponding to the $\mathrm{IC}_{90}$ previously determined for each cell line (50 and $10 \mu \mathrm{M}$ for MDA-MB-231 and MCF7 cells, respectively). Experiments to detect acetylated lysine were performed in the presence of $\mathrm{SAHA} \mathrm{IC}_{50}(5$ and $1 \mu \mathrm{M}$ for MDA-MB-231 and MCF7 cells, respectively), incubating cells for $24 \mathrm{~h}$ in the continous presence of the drug.

In vitro cytotoxicity assay. Drug-induced cytotoxic effects were evaluated by using Alamar Blue assay (18). In brief, MCF7 and MDA-MB-231 cells were seeded into 96-well microtitration plates at $4 \times 10^{3}$ cells/well to ensure a logarithmic growth throughout the experiments. After 24-h of cell attachment, fresh medium containing SAHA at different concentrations was added to each well for further $72 \mathrm{~h}$. At the end of the incubation period, $20 \mu \mathrm{l}$ of Alamar Blue (Biosource International, Camarillo, CA, USA) was added to each well and the plates were further incubated for $4 \mathrm{~h}$. Fluorescence emission was monitored in a multilabel counter Victor 1420 (Wallak, Finland) at 530/590 $\mathrm{nm}$ excitation/emission wavelength. CD137 receptor and CD137 ligand cytotoxic effects were evaluated as follows: MDA-MB-231 cells were plated in 96-well plates at $4 \times 10^{3}$ cells/ well and incubated at $37^{\circ} \mathrm{C}$ in a humidified atmosphere with $5 \% \mathrm{CO}_{2}$. After $24 \mathrm{~h}$, cells were treated in duplicate with fresh medium containing $5 \mu \mathrm{M}$ SAHA alone or in separate mixtures with the following recombinant proteins and antibodies: $1 \mu \mathrm{g} /$ well CD137-hIg, $1 \mu \mathrm{g} /$ well CD137L-muCD8, $2 \mu \mathrm{g} /$ well mouse anti-CD137 mAb (clone 4B4-1) from Ancell (Bayport, MN, USA), $1 \mu \mathrm{g} /$ well mouse anti-CD137L mAb (clone C65-485) and 1-2 $\mu \mathrm{g} /$ well mouse IgG1 control (clone MOPC-21) from BD Bioscience (Franklin Lakes, NJ, USA). Cells were incubated for $0,6,24,48,72 \mathrm{~h}$ at $37^{\circ} \mathrm{C}, 5 \% \mathrm{CO}_{2}$. At the end of the incubation period, $20 \mu \mathrm{l}$ of Alamar Blue was added to each well and the plates were further incubated for $4 \mathrm{~h}$. Fluorescence emission was monitored in a multilabel counter Victor 1420 (Wallak, Finland) at 530/590 nm excitation/emission wavelength.

Tumor xenograft. Female athymic nude mice (6-8 weeks old) were purchased from Charles River (Calco, Lecco, Italy), maintained in microisolator cages and supplied with sterile materials under standard conditions, according to United Kingdom Co-ordinating Committee on Cancer Research guidelines (19). For the generation of MCF7 tumors, female nude mice were first implanted s.c. in the left flank with $17 \beta$-estradiol-sustained release pellets (Innovative Research, Sarasota, FL) and after one week implanted s.c. in the control lateral flank with MCF7 tumor cells $\left(20 \times 10^{6}\right.$ cells/flank/0.2 ml of $0.9 \% \mathrm{NaCl}$ sterile solution). Human tumor MDA-MB-231 originated from s.c. in vivo injection of tumor cells $\left(20 \times 10^{6}\right.$ cells/flank/0.2 ml) in the right flank of adult athymic female nude mice. Tumor volumes were monitored weekly by caliper measurement of length and width twice weekly. Tumor volume (TV) was calculated by using the formula: volume $\left(\mathrm{mm}^{3}\right)=$ width $^{2} \mathrm{x}$ length/2 (20). SAHA was dissolved in DMSO and stored at $-80^{\circ} \mathrm{C}$. This stock solution was diluted just before dosing with D5W (dextrose 5\%) to a final DMSO concentration not superior to $1 \%$. SAHA was administered i.v. at a dose of $50 \mathrm{mg} / \mathrm{kg}$ in a volume corresponding to $10 \mathrm{ml} / \mathrm{kg}$ body weight. Tumor-bearing mice were treated with SAHA or vehicle once daily, 5 days/week, for a total of 10 doses, starting when tumors were approximately $50 \mathrm{~mm}^{3}$ in volume. No adverse or toxic effect were observed at this dose level. All animal experiments were reviewed and approved by the Ethics commission at Menarini Ricerche according to the guidelines of the European Directive for the protection of vertebrate animals used for experimental and other scientific purposes $(2010 / 63 / \mathrm{UE})$.

Apotox assay. MDA-MB-231 cells were plated in 96-well plates at $4 \times 10^{3}$ cells/well and incubated at $37^{\circ} \mathrm{C}$ in a 
humidified atmosphere with $5 \% \mathrm{CO}_{2}$. After $24 \mathrm{~h}$, cells were incubated in duplicate with fresh medium containing $1 \mu \mathrm{M}$ SAHA (synthesized at the Chemistry Department of Menarini Ricerche Pomezia, Rome, Italy), $1 \mu \mathrm{g}$ /well CD137-hIg (Ancell, Bayport, MN, USA), $10 \mu \mathrm{M}$ staurosporine (Sigma) or the mix of $1 \mu \mathrm{M}$ SAHA with $1 \mu \mathrm{g} /$ well CD137-Ig, for $0,6,24,48,72$ and 96-h time points. Cell survival was determined through the ApoTox-Glo Triplex Assay (Promega, Madison, WI, USA), according to the manufacturer's instructions.

Flow cytometric detection of apoptotic cells. Apoptosis was measured by Annexin V-PE/7-ADD staining method (21). Briefly, adherent and floating cells were collected, washed twice with cold PBS and then resuspended in PBS + 0.5\% BSA (staining buffer) at $1 \times 10^{6}$ cells $/ \mathrm{ml}, 3 \times 10^{5}$ cells were transferred in $5 \mathrm{ml}$ culture tube, stained with $15 \mu \mathrm{l}$ of Annexin V-PE and $15 \mu \mathrm{l}$ of 7 -ADD, vortexed and incubated for $15 \mathrm{~min}$ at room temperature in the dark. At the end of the incubation time, $200 \mu \mathrm{l}$ of staining buffer was added to each tube and cells analyzed by flow cytometry collecting 10,000 events on a FACSCanto flow cytometer (BD Biosciences). Data analysis was performed using FacsDiva 6.1.2 version software. Percentage of apoptotic cells was determined setting quadrant gates on the unstained control.

Quantitative analysis of acetylated lysine by flow cytometry. After treatment with the HDACi, cells were trypsinized and fixed in $4 \%$ paraformaldehyde for $10 \mathrm{~min}$ at room temperature. Paraformaldehyde was used for fixation of cells since it has been found to preserve the structure of acetylated chromatin organization. After fixation, cells were washed three times and permeabilized with PBS containing $0.4 \%$ Triton X-100 and $0.1 \%$ BSA. $5 \times 10^{5}$ cells/tube resuspended in PBS $+0.5 \%$ BSA were labelled with a polyclonal rabbit antibody which recognizes hyperacetylated histone $\mathrm{H} 4$ (Upstate Biotechnology) at a dilution of 1:50 for $1 \mathrm{~h}$ at $4^{\circ} \mathrm{C}$. Subsequently, cells were washed twice, incubated with a FITC-conjugated polyclonal anti-rabbit antibody (Santa Cruz Biotechnology) for at least $30 \mathrm{~min}$ at $4^{\circ} \mathrm{C}$ and then resuspended in $1 \mathrm{ml} \mathrm{PBS}+0.5 \% \mathrm{BSA}$. As background controls we used both a specific rabbit IgG and a sample stained only with the secondary antibody. Fluorescence of acetylated lysine was determined on a FacsCanto flow cytometer (BD Biosciences) and expressed in logarithmic arbitrary units as mean fluorescence intensity (MFI). Data analysis was performed using FacsDiva 6.1.2 version software.

Flow cytometric determination of CD137 and CD137L expression. MDA-MB-231 and MCF7 cells were seeded at $5 \times 10^{5}$ cells in T25 flasks, allowed to adhere overnight and next day incubated with 5 or $1 \mu \mathrm{M}$ SAHA for $24 \mathrm{~h}$. Cells were washed with PBS and detached using Trypsin/EDTA solution, counted and resuspended in PBS $+0.5 \%$ BSA (staining buffer) at $10^{7}$ cells/ml. Cells were incubated with FcR blocking buffer for 15 min at room temperature and then $5 \times 10^{5}$ cells transferred in flow cytometric tubes and incubated with $20 \mu \mathrm{l}$ of antiCD137-APC or anti-CD137L-PE antibody or with the isotype matched antibodies and incubated for $30 \mathrm{~min}$ at $4^{\circ} \mathrm{C}$. Cells were washed twice with PBS $+0.5 \%$ BSA (staining buffer) and resuspended in $0.5 \mathrm{ml}$ of the same buffer. Flow cytometric acquisition was performed analyzing 10,000 events on a FacsCanto flow cytometer (BD Biosciences). Background staining for both treated and untreated cells was assessed by incubation of cells with mouse fluorochrome-isotype controls. Background and unstained controls were used to correctly set analysis gates so that CD137- and CD137L-positive quadrants in isotype samples do not contain more than $2 \%$ of cells. Data analysis was performed using FacsDiva 6.1.2 version software.

HDAC activity in cellular extracts. HDAC activity in nuclear extracts was measured according to the manufacturer's instructions (HDAC Fluorescent assay, Biomol International LP, PA). Nuclear extracts were prepared using the kit NE-PER (Pierce Biotechnology) and incubated ( $5 \mu \mathrm{g} /$ well) at $25^{\circ} \mathrm{C}$ with $40 \mu \mathrm{M}$ of Fluor de Lys ${ }^{\mathrm{TM}}$ substrate. Reactions were stopped after $30 \mathrm{~min}$ with Fluor de Lys ${ }^{\mathrm{TM}}$ developer and fluorescence measured using a Victor1420 microplate reader (Wallac, Finland) at ex/em $355 / 460 \mathrm{~nm}$. Results are the mean of three independent experiments \pm SD.

RNA extraction and cDNA synthesis. Total RNA was extracted from cells using the SV Total RNA Isolation System (Cat no. Z3100, Promega, WI, USA). Briefly, cells from $1.5 \times 10^{6}$ to a maximum of $2.5 \times 10^{6}$ per treatment were lysed in $175 \mu \mathrm{l}$ lysis buffer. Lysates were subjected to purification with silica columns according to the instructions of the manufacturer. The yield of total RNA was determined spectrophotometrically at $260 \mathrm{~nm}$, while its integrity was determined by denaturing agarose gel electrophoresis. For each sample, $5 \mu \mathrm{g}$ total RNA were copied into cDNA with the RT2 First Strand Kit (Cat no. C-03, SuperArray, MD, USA). Finished reactions had a volume of $20 \mu \mathrm{l}$ and were stored at $-20^{\circ} \mathrm{C}$ until they were used in realtime PCR analysis.

Gene array analysis by real-time PCR. The cDNA samples were pre-diluted to $100 \mu \mathrm{l}$ and mixed with RT2 qPCR Master Mix (Cat no. PA-012, SuperArray) to a final volume of $2550 \mu 1$. The master mix contains all the reagents and buffers required for the real-time PCR in our 7300 real-time PCR system (Applied Biosystems, CA, USA), including the SYBR Green dye and the ROX reference dye. The gene expression analysis was performed by adding $25 \mu \mathrm{l}$ of the experimental cocktail to each well of a 96-well RT2 Profiler PCR Array for human apoptosis (Cat no. PHAS-012A, SuperArray). In this array, each well contains a primer pair specific for one of 84 key genes involved in human apoptosis, besides housekeeping genes and control wells (Fig. 1). After an initial denaturation at $95^{\circ} \mathrm{C}$ for $10 \mathrm{~min}$, the cycling program was $95^{\circ} \mathrm{C}, 15 \mathrm{sec}$ and $60^{\circ} \mathrm{C}, 1 \mathrm{~min}$ for 40 cycles. Raw data were analyzed with the $\Delta \Delta \mathrm{Ct}$ method using an Excel-based PCR Array Data Analysis Template (SuperArray). Data from control cells were set as calibrator for the relative quantification.

CD137 ligand mRNA by real-time PCR. To determine the mRNA expression levels of target genes, duplicates of the cDNA samples, corresponding to $150 \mathrm{ng}$ of total RNA, were amplified in the presence of $12.5 \mu \mathrm{l}$ of $2 \mathrm{X}$ TaqMan Universal PCR Master Mix and $1.25 \mu \mathrm{l}$ of 20X inventoried TaqMan Gene Expression Assay (Applied Biosystems) to a final volume of $25 \mu \mathrm{l}$. The TaqMan Gene Expression Assays were: Hs00155512_m1 for 

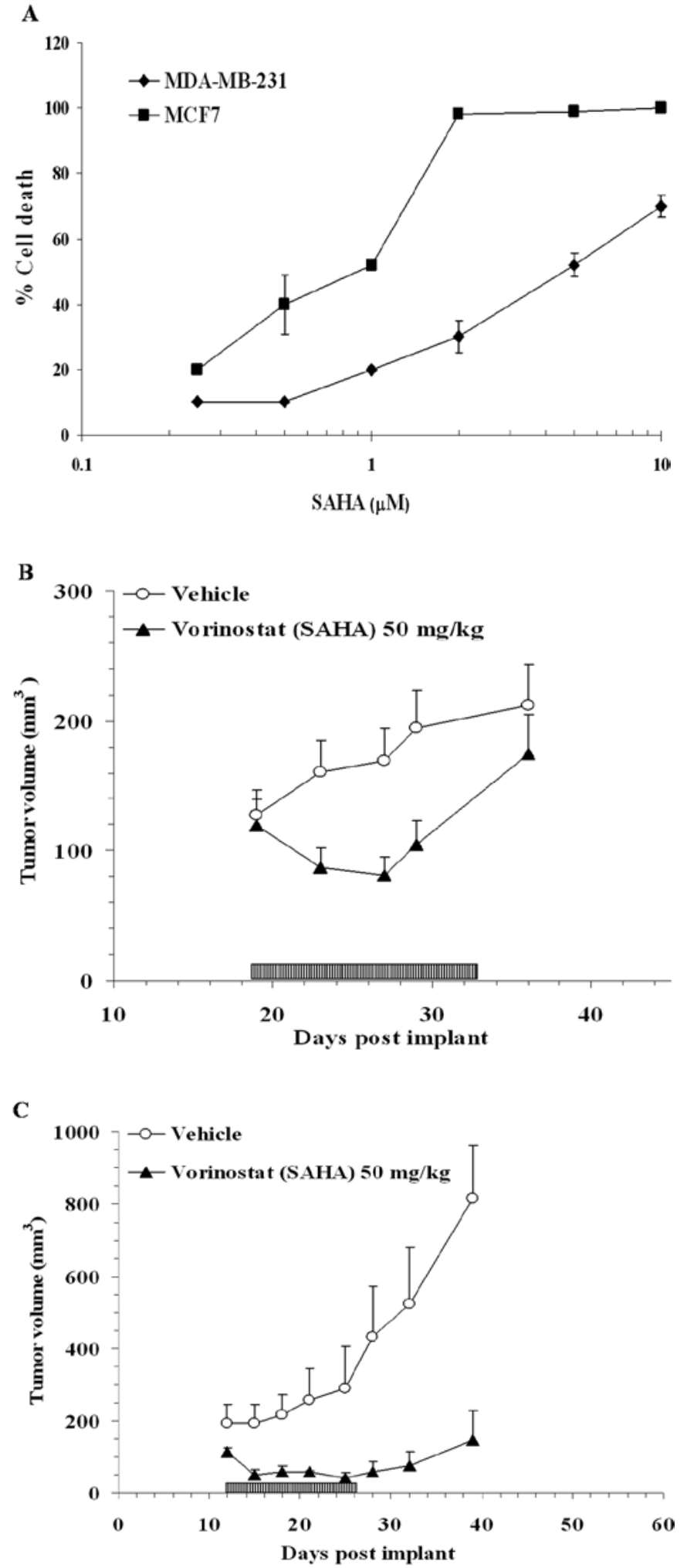

Figure 1. In vitro and in vivo antitumor potency of SAHA. (A), In vitro SAHA cytotoxicity on MDA-MB-231 and MCF7 cells by Alamar Blue assay. (B), Effects of SAHA on in vivo tumor xenograft of MCF7 cells. (C), Effects of SAHA on in vivo tumor xenograft of MDA-MB-231 cells.

TNFRSF9 (CD137), Hs00169409_m1 for TNFSF9 (CD137L) and Hs99999905_m1 for GAPDH. The samples of cDNA were also amplified in the presence of Hs99999903_m1 for human $\beta$-actin to normalize mRNA quantities. After $10 \mathrm{~min}$ of incubation at $95^{\circ} \mathrm{C}$ for denaturation, samples were subjected to
Table I. Apoptosis detection by flow cytometry using Annexin/ 7-ADD method (Materials and methods). ${ }^{a}$

\begin{tabular}{lccc}
\hline & \multicolumn{3}{c}{$\%$ Apoptosis } \\
\cline { 2 - 4 } Cells & Untreated & +SAHA 24 h & +SAHA 48 h \\
\hline MDA-MB-231 & 15 & 43 & 40 \\
MCF7 & 16 & 17 & 45
\end{tabular}

${ }^{\mathrm{a} M D A-M B}-231$ and MCF7 cells were treated with 50 and $10 \mu \mathrm{M}$ SAHA, respectively, for 24 and $48 \mathrm{~h}$.

45 cycles of PCR. Each cycle was $95^{\circ} \mathrm{C}$ for $15 \mathrm{sec}$ and $60^{\circ} \mathrm{C}$ for $1 \mathrm{~min}$. The amplification took place in a 7300 real-time PCR system (Applied Biosystems). The collected data of gene expression were the number of cycles needed to reach a fixed threshold fluorescence $(\mathrm{Ct})$. The gene targets expression in MDA-MB-231 cells treated with $5 \mu \mathrm{M}$ SAHA was then compared to that of untreated cells, selected as calibrator, by processing the obtained $\mathrm{Ct}$ values with the $2^{-\Delta \Delta \mathrm{Ct}}$ method (22).

Statistical analysis. All results were expressed as the mean \pm SD of data obtained from 2 to 3 separate experiments. The data were entered into Instat $2.03 \mathrm{GraphPad}$ software (GraphPad Software Inc., CA, USA) to perform the Student's t-test or the Tukey-Kramer multiple comparison test. Means were considered significantly different at a confidence level of $\mathrm{p}<0.05$. Synergy calculations and extrapolation of CI were performed using the Calcusyn 2.0 version software.

\section{Results}

SAHA-induced cell death in in vitro and in vivo models. In our in vitro Alamar Blue assay, SAHA showed a cytotoxic activity with an $\mathrm{IC}_{50}$ of 5 and $1 \mu \mathrm{M}$ in MDA-MB-231 and MCF7 cells, respectively (Fig. 1A). When xenografted nude mice were treated with SAHA $50 \mathrm{mg} / \mathrm{kg}$ per os, both tumor models, characterised by a different estrogen receptor and p53 status, appeared sensitive to the inhibitory effect of SAHA (Fig. 1B and $\mathrm{C}$ ). A more pronounced and long-lasting inhibition of tumor growth of MDA-MB-231 cells with respect to MCF7 tumor cell line was observed.

Since in several studies it has been described that SAHA exerts its antitumor effect through apoptosis induction, we investigated the presence of apoptotic cell death using the $\mathrm{IC}_{90}$ concentration of this HDACi. Table I shows that, in MCF7 cells, $10 \mu \mathrm{M}$ SAHA causes a slower increase of apoptosis, which at $24 \mathrm{~h}$ measures $17 \%$, compared to the $43 \%$ of $50 \mu \mathrm{M}$ SAHAtreated MDA-MB-231 cells. At 48 h MCF7 cells showed a drastic increase of apoptosis (45\%), while the ER $\alpha$ negative cells remained quite stable (40\%). Thus, the kinetics of SAHAinduced apoptosis in these cell lines seems to be quite different, probably because of the distinct pathways involved (see below). Flow cytometric analysis of cell cycle phases in MDA-MB-231 and MCF7 cells at 50 and $10 \mu \mathrm{M}$ of SAHA, respectively, for $24 \mathrm{~h}$, revealed only a moderate block in $\mathrm{G} 2 / \mathrm{M}$ phase and a reduction of S-phase in MDA-MB-231 cells and a more potent growth arrest and G2/M block in MCF7 cells (data not shown). 


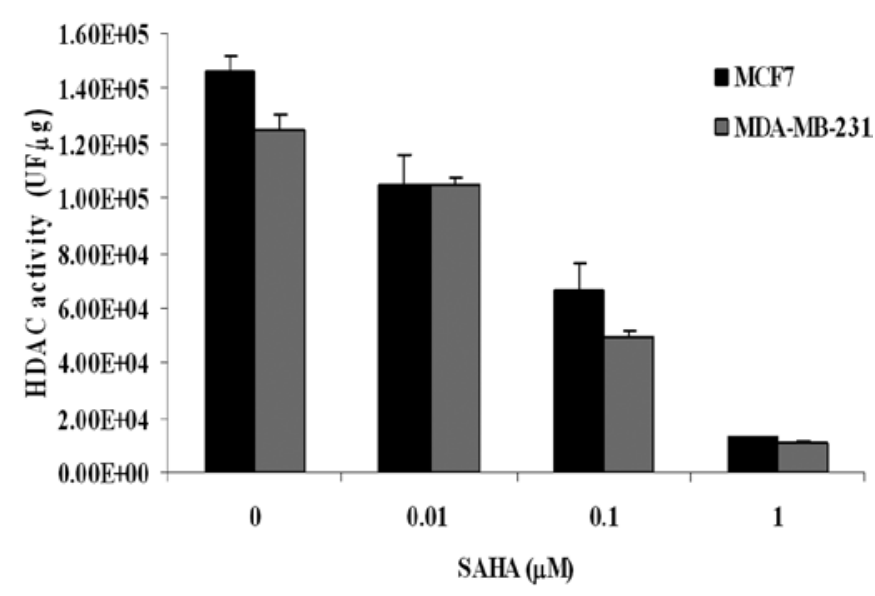

Figure 2. HDAC activity in nuclear extracts of MDA-MB-231 or MCF7 cells in the presence of different concentrations of SAHA. Results are the mean of three independent experiments $\pm \mathrm{SD}$.

These results are in agreement with the cytotoxicity assay, confirming a lower in vitro sensitivity of MDA-MB-231 cells also to SAHA-induced apoptotic cell death.

H4 histone acetylation and inhibition of HDAC activity. As shown in Fig. 2, when HDAC activity was measured in nuclear extracts, we found that SAHA exerted an inhibitory effect that was quite similar between MDA-MB-231 and MCF7 cells. The flow cytometric analysis of $\mathrm{H} 4$ histone acetylation revealed that, in untreated MDA-MB-231 cells, the basal level of acetylation was higher than that measured in MCF7 cells. When cells were incubated for $24 \mathrm{~h}$ with equitoxic concentration of $\mathrm{SAHA}\left(\mathrm{IC}_{50}\right)$, an increase of histone acetylation was observed, and again it was more pronounced in MDA-MB-231 than in MCF7 cells (percentage increase of $75 \%$ and $21 \%$, respectively) (Table II). Since histone acetylation favours chromatin relaxation and gene expression, this observation seems to correlate well with the earlier induction of apoptosis seen at $24 \mathrm{~h}$ in MDA-MB-231 cells.

Effect of SAHA on apoptotic gene expression. When we investigated the pattern of apoptotic genes induced or repressed by SAHA (Fig. 3A), we found that, in the two human breast tumor cell lines, mRNAs related to different apoptotic pathways were expressed. Variations with more than 3-fold increase/decrease have been considered significant. In MDA-MB-231 cells an upregulation of genes which are associated to the extrinsic apoptotic death receptor pathway was observed, such as TNFSF10 (TRAIL), TNFSF8 (CD30L), CD27, CD70, TNFRSF25 (DR3), caspase 8 . In particular a strong upregulation (more than 10-fold) of TNFRSF9 (CD137 receptor) and of CD137 ligand transcription has been measured (Fig. 3) and protein expression confirmed by flow cytometry (Fig. 4). Factors involved into the mitochondrial pathway were not particularly affected in this cell line. On the contrary, in MCF7 cells, the intrinsic apoptotic pathway seems to be involved: in fact the TNF-superfamily genes were not induced by SAHA treatment, but genes encoding for proapoptotic factors such as p53 binding protein 2 (TP53BP2) and BNIP3 were upregulated. Furthermore, in MDA-MB-231 cells, caspases 4, 5 and 7 rather then caspase 3 seem to be
Table II. Flow cytometric determination of H4 histone acetylation.

\begin{tabular}{lcc}
\hline Treatment & MDA-MB-231 (MFI) & MCF7 (MFI) \\
\hline Blank & 26 & 14 \\
No drug & 306 & 75 \\
SAHA & $536(+75 \%)$ & $91(+21 \%)$ \\
\hline
\end{tabular}

${ }^{a}$ Cells were stained by indirect immunofluorescence using a rabbit polyclonal antibody against hyperacetylated histone $\mathrm{H} 4$ as primary antibody. Acetylation is measured in logarithmic arbitrary units as mean fluorescence intensity (MFI). In brackets the percentage increase of MFI following SAHA treatment. Blank is an untreated sample only stained with the FITC-conjugated secondary antibody.

activated while in MCF7 cells, which are caspase 3-deprived, we observed a strong increase of caspase 14 mRNA, suggesting that in this cell line this caspase could become the final effector of the apoptotic signalling.

Effect of the combination of SAHA and soluble CD137 on cytotoxicity/apoptosis in MDA-MB-231 cells. To assess the existence of a functional significance of CD137 receptor/ligand upregulation, we combined treatment of SAHA with soluble CD137 receptor and related molecules. Fig. 5A shows that the simultaneous administration of $5 \mu \mathrm{M}$ SAHA with the soluble form of CD137 receptor induced the most significant enhancement of cell death, when compared to single-drug conditions or to the combination with other agonists (Fig. 5B-D). When $1 \mu \mathrm{M}$ SAHA was assayed in the Apotox assay in order to reduce the cytotoxicity of single-drug treatment, a more pronounced effect was observed, with a synergism of action (CI 0.24) at the 72-h time point (Fig. 6).

\section{Discussion}

In the present study we showed for the first time that an HDACi promotes CD137/CD137L upregulation in a solid tumor in particular in a breast cancer cell line. Moreover, we found that the simultaneous administration of SAHA and soluble CD137 receptor exerts a synergistic effect on cancer cell destruction.

Many investigators have demonstrated that HDACis exert their anticancer activity by inducing apoptosis and modulating the in vivo environment of tumor cells $(7,23,24)$. Furthermore, it has been also described that HDACis sensitize breast cancer cells to TRAIL induced apoptosis $(25,26)$, while a recent paper of Vire et al reported CD137/CD137L induction by HDACis in haematological cancer cells (27), however, many aspects of their in vivo cytotoxic action remain to be elucidated. Our findings demonstrated that, in MCF7 cells, SAHA activates the intrinsic apoptotic pathway through induction of genes related to p53 signalling, while, in MDA-MB-231 cells, SAHA treatment increases the transcription of genes involved in the cell death pathway, such as TNFSF10 (TRAIL), caspase 8, and even more the genes encoding for the CD137 and CD70 receptor/ligand system. The CD137 receptor (TNFRSF9, 4-1BB, ILA) is a member 
A
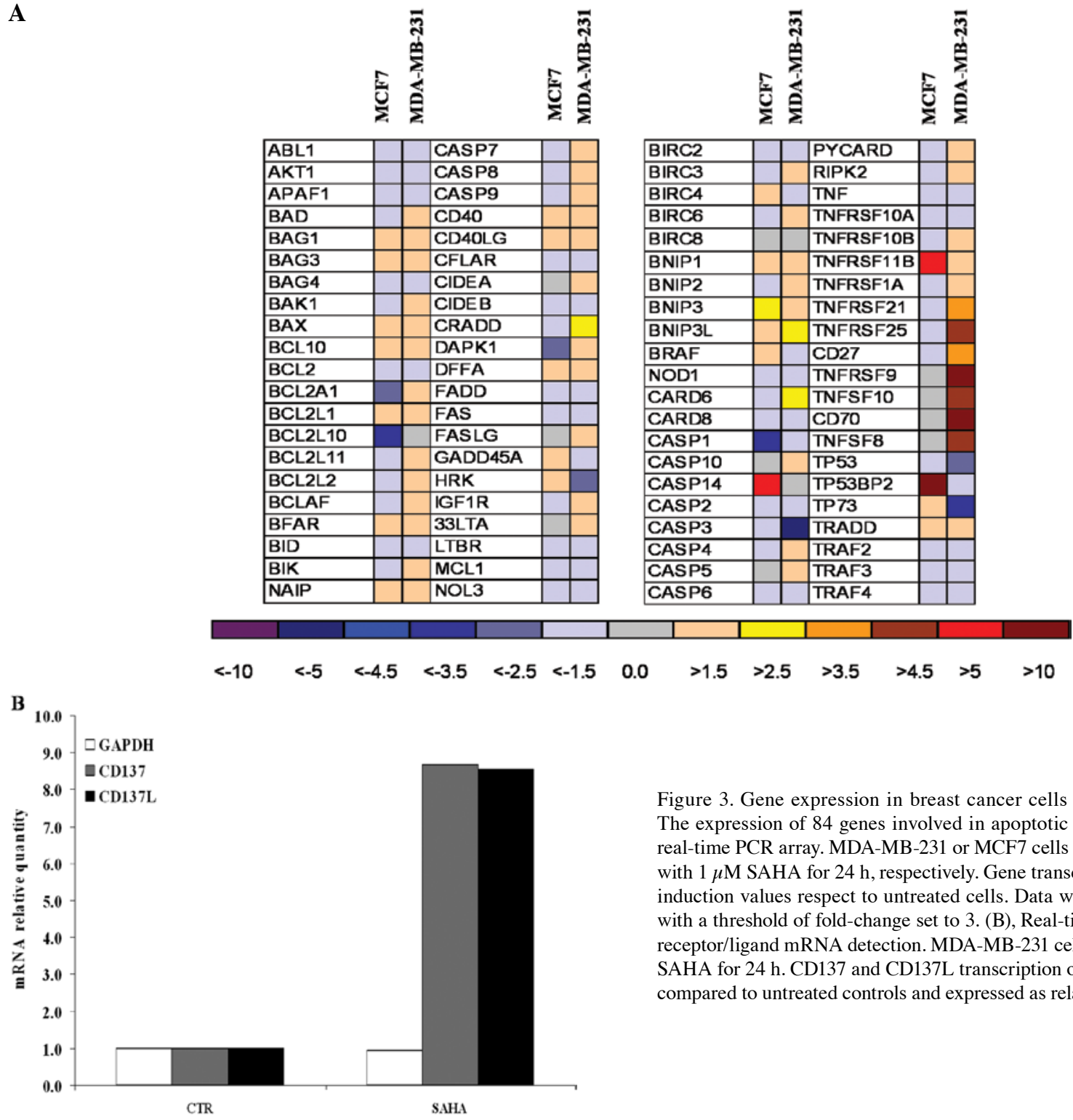

Figure 3. Gene expression in breast cancer cells treated with SAHA. (A), The expression of 84 genes involved in apoptotic pathway was assayed by real-time PCR array. MDA-MB-231 or MCF7 cells were treated with $5 \mu \mathrm{M}$ or with $1 \mu \mathrm{M} \mathrm{SAHA}$ for $24 \mathrm{~h}$, respectively. Gene transcription is reported as fold induction values respect to untreated cells. Data were considered significant with a threshold of fold-change set to 3. (B), Real-time PCR assay for CD137 receptor/ligand mRNA detection. MDA-MB-231 cells were treated with $5 \mu \mathrm{M}$ SAHA for $24 \mathrm{~h}$. CD137 and CD137L transcription of SAHA-treated cells was compared to untreated controls and expressed as relative quantity.

$\mathbf{A}$

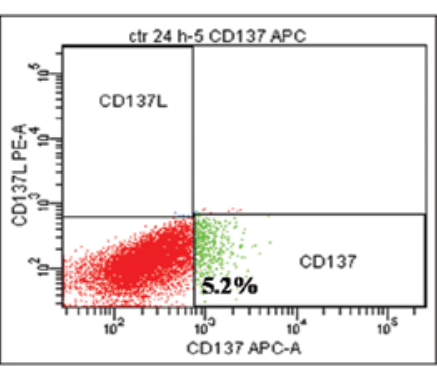

D

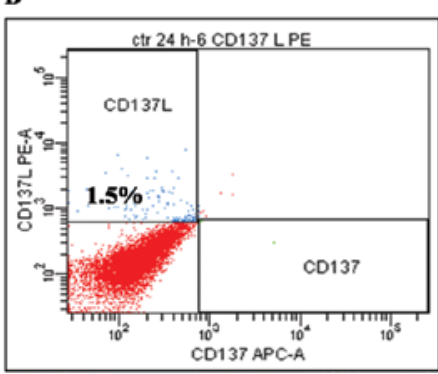

B

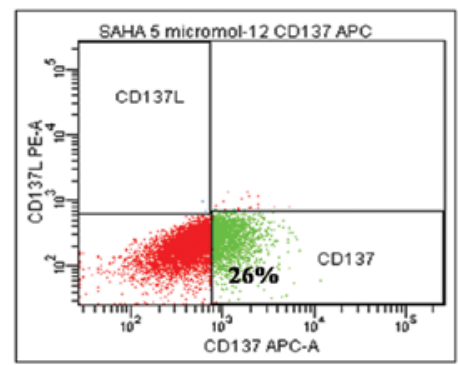

E

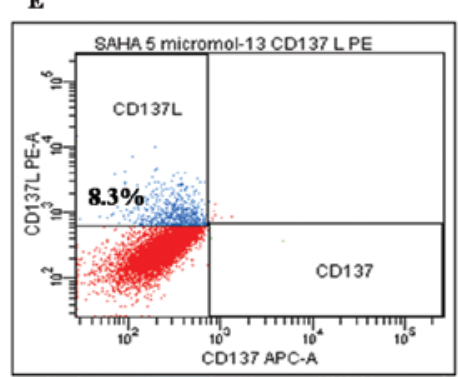

C 1 MM SAHA

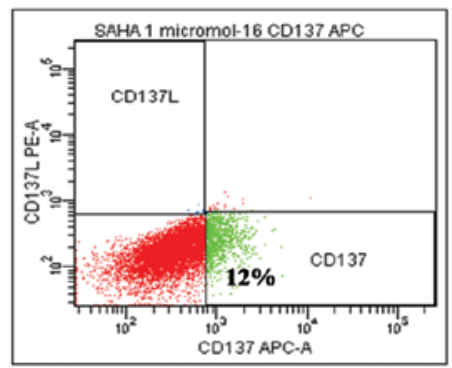

$\mathbf{F}$

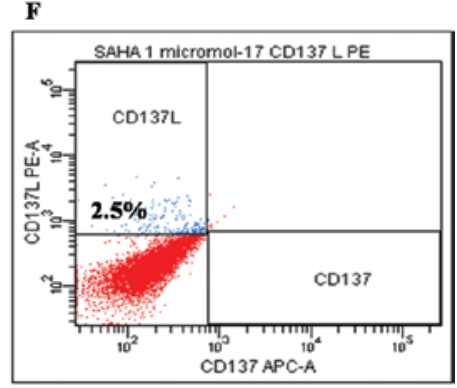

Figure 4. Flow cytometric determination of CD137 receptor/ligand proteins. MDA-MB-231 cells were treated for $24 \mathrm{~h}$ with $5 \mu \mathrm{M}$ or $1 \mu \mathrm{M}$ SAHA. (A-C), CD137 receptor expression. (D-F), CD137L expression. 

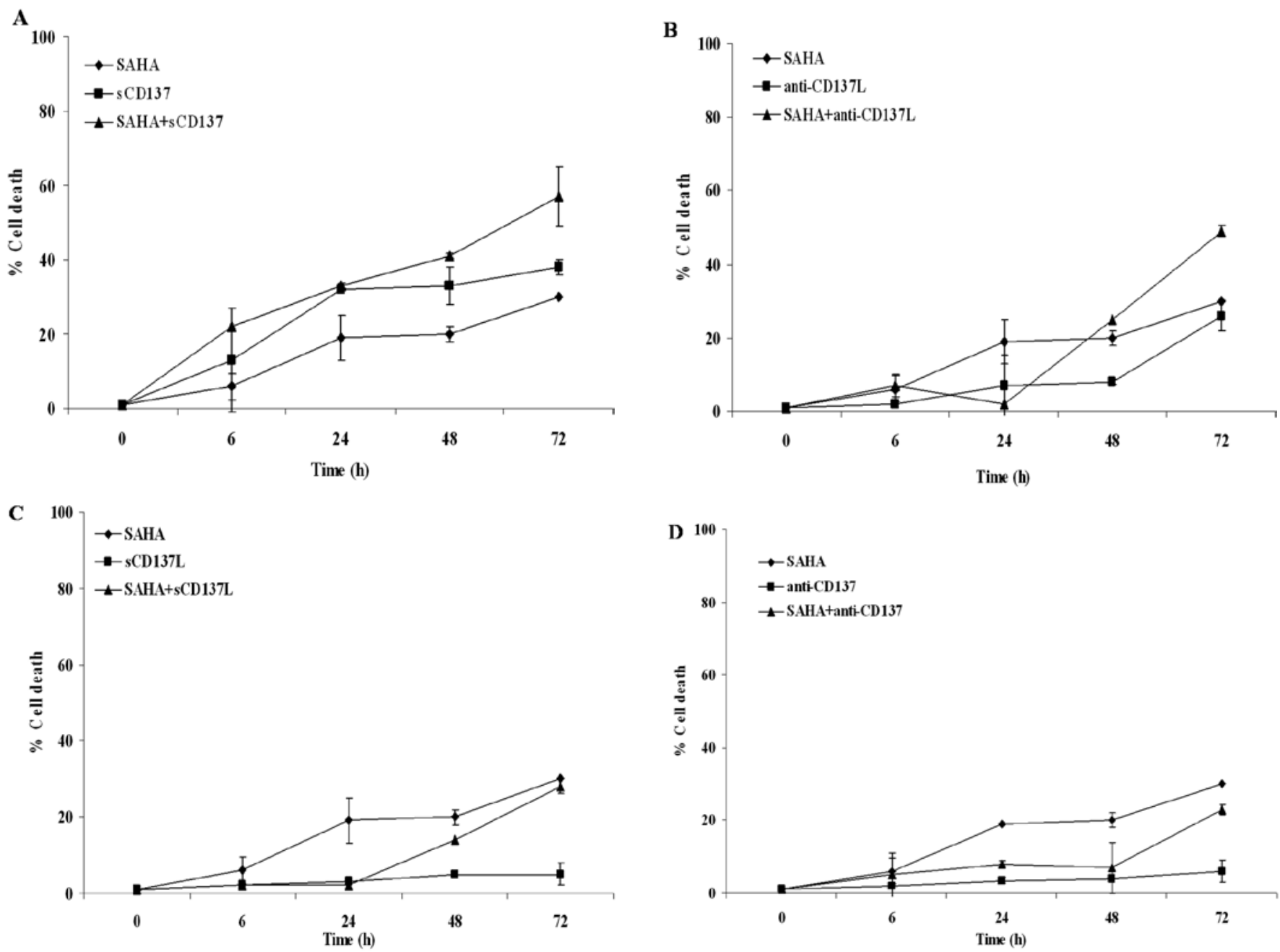

Figure 5. In vitro cytotoxicity on MDA-MB-231 cells of $5 \mu \mathrm{M}$ SAHA in combination or not with: (A), soluble CD137 receptor (sCD137). (B), Anti-CD137L antibody (anti-CD137L). (C), Soluble CD137L (sCD137L). (D), Anti-CD137 antibody (anti-CD137). Cell death was measured by Alamar Blue assay.

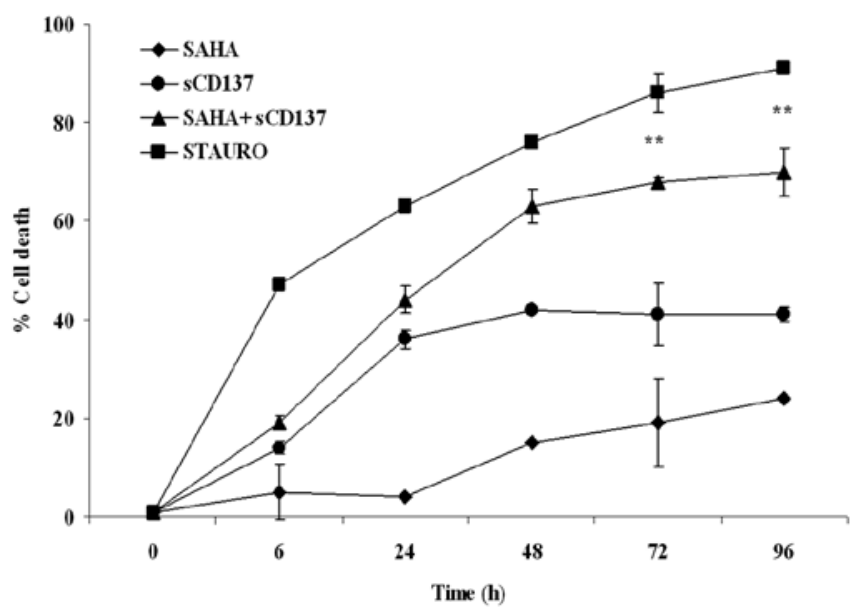

Figure 6. Kinetics of apoptosis induction in MDA-MB-231 cells. Breast cancer cells were treated with $10 \mathrm{mg}$ soluble CD137 receptor (sCD137) in combination or not with $1 \mu \mathrm{M}$ SAHA. ${ }^{* *} \mathrm{p}<0.01$ at Tukey-Kramer multiple comparison test.

of the tumor necrosis factor receptor family, and a potent $\mathrm{T}$ cell co-stimulatory molecule. Its natural ligand, CD137 ligand
(TNFSF9, CD137L-4-1BBL), has been detected on professional APCs including B cells, macrophages, dendritic cells and can transduce signals, a process known as 'reverse signalling' $(28,29)$. The bidirectional signalling of CD137L usually induces activation, proliferation and migration of monocytes and hematopoietic progenitor cells. However, a recent study reported that $\mathrm{CD} 137 \mathrm{~L}$ engagement can also inhibit cell proliferation and induce apoptosis in multiple myeloma cell lines (30). Other receptors, such as CD40, have shown a similar double behaviour, suggesting that the final effect of these receptor/ ligand systems is probably dependent on tumor cell type and on the induction of other bifunctional molecules (31). Our data showed also that the stimulation of CD137 receptor was not particularly effective in increasing cell death, despite its higher expression on MDA-MB-231 cells, and no synergism or additive effect was measured following combination of SAHA with CD137L or with an anti-CD137 antibody. Thus these results seem to confirm the observations of Gullo et al on the prevalent role of CD137L in activating a cell death signal in human tumor cells (30). Furthermore, the presence of a mutated p53 in this cell line, could account for the activation of the extrinsic apoptotic pathway and for its in vitro reduced sensitivity to SAHA. Recent studies reported that 
re-expression of CD70 in tumor cells may induce an anti-tumor response by T-lymphocytes and that the epigenetic downregulation of CD70 receptor by DNA hypermethylation is a strategy of breast cancer cells to escape immune response (32). Our observation that SAHA-induced histone hyperacetylation determines also an overexpression of CD70 and CD27 in MDA-MB-231 cells, supports the idea that SAHA treatment could restore an immune response against cancer cells. So our initial results showing that MDA-MB-231 cells are more sensitive to SAHA treatment in the in vivo tumor xenograft model than in in vitro assays, when compared to the MCF7 cell line, could be explained by the concurrent overexpression of multiple death receptors/ligands. Since in solid tumors the presence of soluble forms of CD137, TRAIL and of autocrine and paracrine factors which affect cancer development has been documented $(33,34)$, it is possible that the stimulation of overexpressed receptors/ligands contributes to the enhancement of apoptosis and to the regression of tumor mass.

In conclusion, our study demonstrated that SAHA can activate different apoptotic genes and targets depending on the type of breast cancer cell line studied, and that promotes, in a p53-mutated breast cancer cell line, the expression of cell death molecules such as CD137/CD137L. These findings suggest that the induction of death receptors could contribute to enhancing in vivo SAHA activity on breast tumors and that the combination of SAHA with soluble CD137 receptor could be a new further approach in breast cancer therapy.

\section{Acknowledgements}

We would like to thank the Department of Chemistry of Menarini Ricerche, Pomezia, for the synthesis of SAHA.

\section{References}

1. Grunstein M: Histone acetylation in chromatin structure and transcription. Nature 389: 349-352,1997.

2. Glass CK and Rosenfeld MG: The coregulator exchange in transcriptional functions of nuclear receptors. Genes Dev 14: 121-141, 2000.

3. Grignani F, De Matteis S, Nervi C, Tomassoni L, Gelmetti V, Cioce M, Fanelli M, Ruthardt M, Ferrara FF, Zamir I, Seiser C, Grignani F, Lazar MA, Minucci S and Pelicci PG: Fusion proteins of the retinoic acid receptor- $\alpha$ recruit histone deacetylase in promyelocytic leukaemia. Nature 391: 815-818, 1998.

4. Garcia-Manero G, Yang H, Bueso-Ramos C, et al: Phase 1 study of the histone deacetylase inhibitor vorinostat (suberoylanilide hydroxamic acid [SAHA]) in patients with advanced leukemias and myelodysplastic syndromes. Blood 111: 10601066,2008

5. Blumenschein GR Jr, Kies MS, Papadimitrakopoulou VA, Lu C, Kumar AJ, Ricker JL, Chiao JH, Chen C and Frankel SR: Phase II trial of the histone deacetylase inhibitor (Zolinza, suberoylanilide hydroxamic acid, SAHA) in patients with recurrent and/or metastatic head and neck cancer. Invest New Drugs 26: 81-87, 2008.

6. Xu WS, Parmigiani RB and Marks PA: Histone deacetylase inhibitors: molecular mechanisms of action. Oncogene 26: 5541-5552, 2007.

7. Qian DZ, Kato Y, Shabbeer S, Wei Y, Verheul HM, Salumbides B, Sanni T, Atadja P and Pili R: Targeting tumor angiogenesis with histone deacetylase inhibitors: the hydroxamic acid derivative LBH589. Clin Cancer Res 12: 634-642, 2006.

8. Bertino E and Otterson GA: Romidepsin: a novel histone deacetylase inhibitor for cancer. Expert Opin Investig Drugs 20: 1151-1158, 2011.
9. Ramalingam SS, Kummar S, Sarantopoulos J, Shibata S Lo Russo P, Yerk M, Holleran J, Lin Y, Beumer JH, Harvey RD, Ivy SP, Belani CP and Egorin MJ: Phase I study of vorinostat in patients with advanced solid tumors and hepatic dysfunction: a National Cancer Institute Organ Dysfunction Working Group study. J Clin Oncol 28: 4507-4512, 2010.

10. Butler LM, Zhou X, Xu WS, Scher HI, Rifkind RA, Marks PA and Richon VM: The histone deacetylase inhibitor SAHA arrests cancer cell growth, up-regulates thioredoxin-binding protein-2, and down-regulates thioredoxin. Proc Natl Acad Sci USA 99: 11700-11705, 2002.

11. Cohen LA, Marks PA, Rifkind RA, Amin S, Desai D, Pittman B and Richon VM: Suberoylanilide hydroxamic acid (SAHA), a histone deacetylase inhibitor, suppresses the growth of carcinogen-induced mammary tumors. Anticancer Res 22: 1497-1504, 2002.

12. Nakata S, Yoshida T, Horinaka M, Shiraishi T, Wakada M and Sakai T: Histone deacetylase inhibitors upregulate death receptor 5/TRAIL-R2 and sensitize apoptosis induced by TRAIL/ APO2-L in human malignant tumor cells. Oncogene 23: 6261-6271, 2004.

13. Guo F, Sigua C, Tao J, Bali P, George P, Li Y, Wittmann S, Moscinski L, Atadja P and Bhalla K: Cotreatment with histone deacetylase inhibitor LAQ824 enhances Apo-2L/tumor necrosis factor-related apoptosis inducing ligand-induced death inducing signaling complex activity and apoptosis of human acute leukemia cells. Cancer Res 64: 2580-2589, 2004.

14. Kim MS, Blake M, Baek JH, Kohlhagen G, Pommier Y and Carrier F: Inhibition of histone deacetylase increases cytotoxicity to anticancer drugs targeting DNA. Cancer Res 63: 7291-7300, 2003.

15. Jang ER, Lim SJ, Lee ES, Jeong G, Kim TY, Bang YJ and Lee JS: The histone deacetylase inhibitor trichostatin A sensitizes estrogen receptor $\alpha$-negative breast cancer cells to tamoxifen. Oncogene 23: 1724-1736, 2004

16. Licznar A, Caporali S, Lucas A, Weisz A, Vignon F and Lazennec G: Identification of genes involved in growth inhibition of breast cancer cells transduced with estrogen receptor. FEBS Lett 553: 445-450, 2003.

17. Srivastava RK, Kurzrock R and Shankar S: MS-275 sensitizes TRAIL-resistant breast cancer cells, inhibits angiogenesis and metastasis and reverses epithelial-mesenchymal transition in vivo. Mol Cancer Ther 9: 3254-3266, 2010.

18. Page B, Page M and Noel C: A new fluorimetric assay for cytotoxicity measurements in vitro. Int J Oncol 3: 473-476, 1993.

19. Workman P, Aboagye EO, Balkwill F, et al: Guidelines for the welfare and use of animals in cancer research. Br J Cancer 102: 1555-1577, 2010.

20. Plowman J, Dykes DJ, Melinda H, Simpson-Hellen L and Alley MC: Human tumor xenograft models in NCI drug development. In: Anticancer Drug Development Guide. Teicher BA (ed). Humana Press, Totowa, NJ, pp101-126, 1997.

21. Koopman G, Reutelingsperger CP, Kuijten GA, Keehnen RM, Pals ST and van Oers MH: Annexin V for flow cytometric detection of phosphatidylserine expression on $\mathrm{B}$ cells undergoing apoptosis. Blood 84: 1415-1420, 1994.

22. Livak KJ: ABI Prism 7700 Sequence Detection System. User Bulletin No. 2. PE Applied Biosystems AB website, Bulletin Reference 4303859B 77802-002, 1997.

23. Archer SY, Johnson J, Kim HJ, Ma Q, Mou H, Daesety V, Meng $S$ and Hodin RA: The histone deacetylase inhibitor butyrate downregulates cyclin $\mathrm{B} 1$ gene expression via a $\mathrm{p} 21$ / WAF-1-dependent mechanism in human colon cancer cells. Am J Physiol Gastrointest Liver Physiol 289: G696-G703, 2005.

24. Hellebrekers DM, Melotte V, Viré E, Langenkamp E, Molema G, Fuks F, Herman JG, van Criekinge W, Griffioen AW and van Engeland M: Identification of epigenetically silenced genes in tumor endothelial cells. Cancer Res 67: 4138-4148, 2007.

25. Kim HR, Kim E-J, Yang S-H, Jeong E-T, Park C, Lee J-H, Youn M-J, So H-S and Park R: Trichostatin A induces apoptosis in lung cancer cells via simultaneous activation of the death receptormediated and mitochondrial pathway. Exp Mol Med 38: 616-624, 2006.

26. Shankar S, Davis R, Singh KP, Kurzrock R, Ross DD and Srivastava RK: Suberoylanilide hydroxamic acid (Zolinza/vorinostat) sensitizes TRAIL-resistant breast cancer cells orthotopically implanted in BALB/c nude mice. Mol Cancer Ther 8: 1596-1605, 2009. 
27. Vire B, De Walque S, Restouin A, Olive D, van Lint C and Collette Y: Anti-leukemia activity of MS-275 histone deacetylase inhibitor implicates 4-1BBL/4-1BB immunomodulatory functions. PLoS One 4: e7085, 2009.

28. Sun Y, Chen JH and Fu Y: Immunotherapy with agonistic antiCD137: two sides of a coin. Cell Mol Immunol 1: 31-36, 2004.

29. Shao Z and Schwarz H: CD137 ligand, a member of the tumor necrosis factor family, regulates immune responses via reverse signal transduction. J Leukoc Biol 89: 21-29, 2011.

30. Gullo C, Koh LK, Pang WL, Ho KT, Tan SH and Schwarz H: Inhibition of proliferation and induction of apoptosis in multiple myeloma cell lines by CD137 ligand signaling. PLoS One 5: e10845, 2010.

31. Tai YT,Catley LP,Mitsiades CS, Burger R, Podar K, Shringpaure R, Hideshima T, Chauhan D, Hamasaki M, Ishitsuka K, Richardson P, Treon SP, Munshi NC and Anderson KC: Mechanisms by which SGN-40, a humanized anti-CD40 antibody, induces cytotoxicity in human multiple myeloma cells: clinical implications. Cancer Res 64: 2846-2852, 2004.
32. Yu SE, Park SH and Jang YK: Epigenetic silencing of TNFSF7 (CD70) by DNA methylation during progression to breast cancer. Mol Cells 29: 217-221, 2010.

33. Dimberg J, Hugander A and Wagsater D: Expression of CD137 and CD137L in colorectal cancer patients. Oncol Rep 15: 1197-1200, 2006.

34. Nicolin V and Narducci P: Soluble TRAIL could enhance bone destruction acting on Rank-ligand in estrogen-independent human breast cancer cell line MDA-MB-231. Acta Histochem 112: 1189-1192, 2010. 